\title{
Economic Assessment of Railway Policies: High Speed or High- Performance. A Case of Study
}

\author{
Pablo Coto-Millán ${ }^{*},{ }^{2}$ Pedro Casares ${ }^{1}$ and Vicente Inglada ${ }^{2}$ \\ ${ }^{I}$ Department of Economics, University of Cantabria, Spain \\ ${ }^{2}$ Department of Economics, University of Complutense, Madrid, Spain
}

\begin{abstract}
The objective of the present paper is to assess the railway investment project in Spain for the Santander-Madrid route, using the Cost-Benefit Analysis method. The paper aims at answering the following question - what is more viable: a High Speed Train for passengers between Santander and Madrid, or rather a High Performance Train for passengers and cargo between Santander and Madrid? Being able to answer this question is clearly key information for investment decision making in the field of government's or country's transport policy. In this study, a Cost-Benefit Analysis with two options for the railway project has been calculated: only passengers and combined passengers-cargo. In this case, results favour the passengers-cargo option rather than its alternative.
\end{abstract}

Keywords: High speed train; high performance train; cost-benefit analysis; demand.

\section{INTRODUCTION}

In this study, a railway investment project that will connect Santander and Madrid is analysed. This analysis extends not only to the transport of passengers, which will be called "High Speed Train option", but also to the possibility of transporting both passengers and cargo, which will be referred to as "High Performance Train option".

The cost-benefit analysis method applied to the high speed railway from Santander-Palencia-Valladolid-Madrid establishes its economic profitability by calculating the present discounted value of its net social benefits and the corresponding internal rates of return of the investment. Lastly, the most relevant conclusions regarding the economic assessment of the passengers-only project and the combined passengers and cargo option will be offered.

The first assumption made is that the Madrid-ValladolidPalencia section of railway shall be finished before 2010, when works are due to start on the high speed or high performance railway track from Santander to Palencia. For this reason, the latter project is the only one to be taken into account for this cost-benefit analysis, given that the MadridValladolid section is sufficiently justified by its centres of population and the Valladolid-Palencia section is justified in its Palencia-León-Oviedo-Gijón connection. This assumption will evidently facilitate the profitability of the project. It is, in short, a reflection of the network benefits related to the construction of transport infrastructure.

The Santander-Palencia line will integrate Cantabria into the Spanish high speed railway network. The line will connect Santander to Madrid in less than 2 hours 25 minutes at high speed. It will also make it possible to carry freight

*Address correspondence to this author at the Department of Economics, University of Cantabria, Spain; Tel: +34 942201653; Fax: +34 942 201603; E-mail: cotop@unican.es between both cities using this line. It has two differentiated sections;

Palencia-Alar del Rey. Its survey report was approved on April 1st, 2003 and the corresponding four construction projects are currently being drafted: Palencia-Amusco, Amusco-Marcilla, Marcilla de Campos-Villaprovedo and Villaprovedo-Alar del Rey.

Alar del Rey-Santander. The survey report, approved on May 23rd, 2003, and which is currently being subject of environmental regulation procedures, divides the high speed line into three sections: Alar del Rey-Reinosa, Reinosa-Los Corrales de Buelna and Los Corrales de Buelna-Santander. New line routes will be created for the first two sections, whereas for the third section the existing line will be duplicated.

To help readers visualizing the corridor under study, the Fig. (1) has been included:

\section{METHODOLOGY: SANTANDER-PALENCIA COST- BENEFIT ANALYSIS}

The methodology used for the assessment of social benefits in the cost-benefit analysis of this project is a generalisation of the method used in [1] and extensively described in $[2,3]$ for the case of the high speed train from Madrid-Sevilla and in $[4,5]$ for the high speed train from Madrid-Barcelona-French Border.

Undoubtedly, it is necessary to collect a huge amount of data from the corridor Madrid-Sevilla to apply them to the Palencia- Santander corridor. The reason for choosing this corridor is that it was the first one constructed in the country, which means there are more data and experiences available. It has been assumed that mistakes occurred at collecting data from a corridor and applying them to the other are not significant.

This framework has been extended with the methodology employed for the assessment of transport externalities 


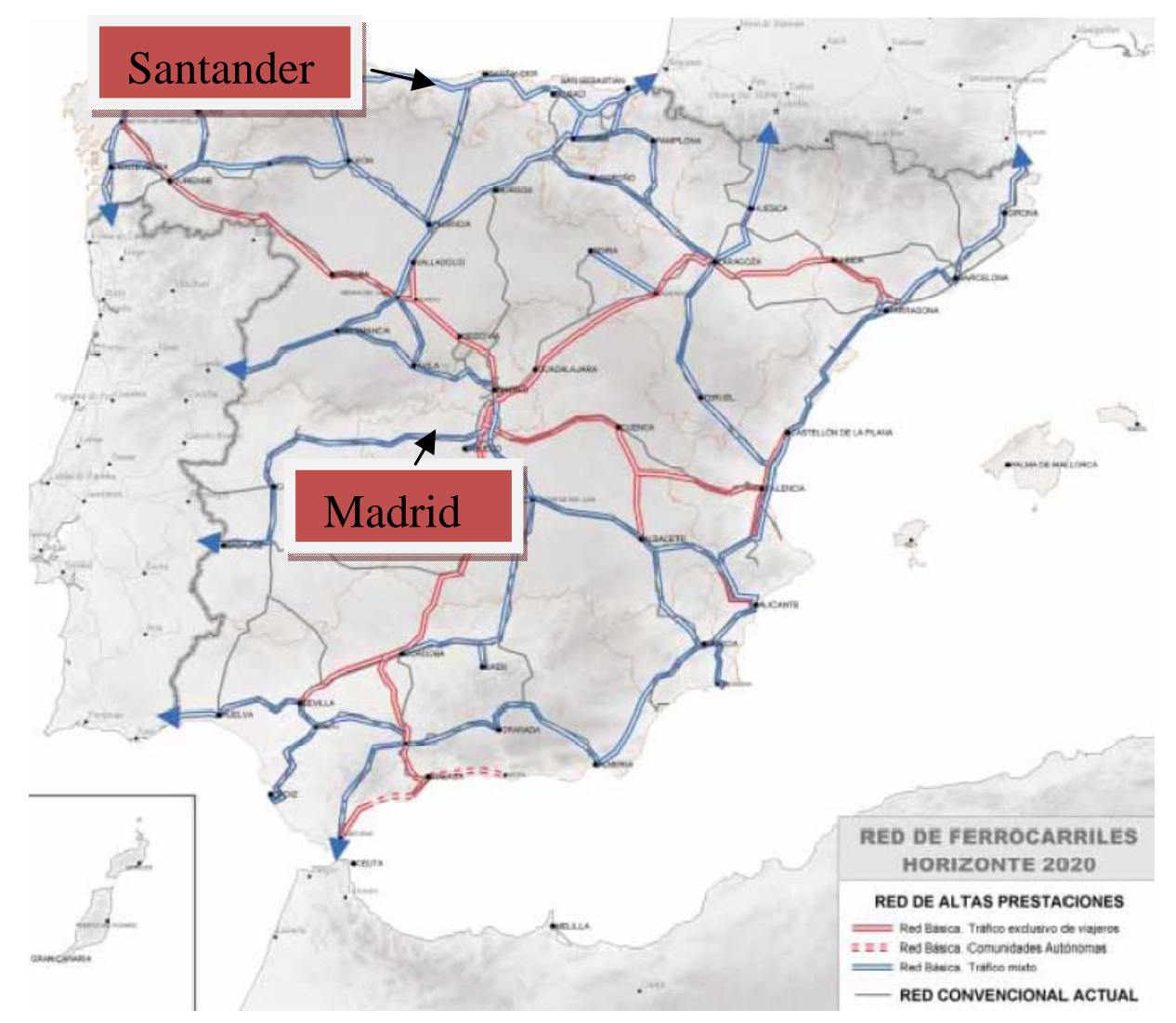

Fig. (1). Spanish high speed network, horizon 2020.

detailed in [6]. For the quantification of the external costs of the different modes of passenger transport (high speed railway -hereafter AVE-, private vehicle, conventional railway and airplane), and of cargo transport (lorry and railway), it is necessary to determine the balance of social benefits related to the introduction of the AVE.

The externalities considered are: maintenance of the infrastructure (for conventional railway and road); traffic congestion (for road), accidents (for conventional railway and road) and the environment (noise, pollution and climate change for all modes of transport).

In addition, all characteristic assessment criteria for the social assessment of projects have been used: shadow pricing, tax exclusion etc., as detailed in [6].

Table 1 shows the summary of costs and benefits considered in the assessment of this project.

According to [5], the method for assessing costs and benefits is as follows.

\subsection{Monetary Costs}

The project costs can be divided into fixed, semi-fixed and variable, naturally depending on the term considered. Fixed costs are those corresponding to the construction of the infrastructure (in the widest sense) and its maintenance. Semi-fixed costs correspond to the purchase of rolling stock and, lastly, variable costs are those commonly called operating costs, characterised by being highly sensitive to the evolution of the demand. All taxes such as IVA (VAT) are excluded from each cost category.
Table 1. Costs and Benefits of the AVE Santander-Madrid Project

\begin{tabular}{|ll|}
\hline \multicolumn{1}{|c|}{ Costs } & \multicolumn{1}{c|}{ Benefits } \\
\hline \hline $\begin{array}{l}\text { Total cost of infrastructure, } \\
\text { maintenance and operation } \\
\text { (TC= I - R + RS + IM + O) }\end{array}$ & Total benefits \\
(IGT + TS + CR + REC) \\
\hline Infrastructure (I) & Income from Generated \\
Trips (IGT) \\
Residual value (R) & Time saving (TS) for users from: \\
Rolling Stock (RS) & Other methods of transport \\
Infrastructure maintenance (IM) $)$ & Cost reduction (CR) in: \\
Operation (O) & Conventional railway \\
& Airplane \\
& Coaches \\
& Operational car costs \\
& Reduction of external \\
& costs (REC) in: \\
& Congestion \\
& Accidents \\
& Environment \\
& Infrastructure maintenance \\
\hline
\end{tabular}

Source: Authors' compilation based on [4-6].

With regard to the prices, the assumption that all categories of the assessment are valued at constant 2008 prices has been adopted. 
The methodology used for the quantification of each one of the mentioned cost categories is the following:

\section{Costs of Infrastructure Construction}

The AVE Santander-Palencia infrastructure includes the track as well as the earthworks, signalling, stations, catenary, etc. It has been assumed that building would start in 2011 and would finish in 2016. The total cost of the 201 kilometres amounts to 1,413 million Euro in 2008. Of this amount, $325 \mathrm{M}$ Euro correspond to the Palencia-Alar del Rey section and 1,088 M Euro to the Alar del Rey-Santander section, according to the corresponding survey reports. Each kilometre of built infrastructure amounts to a cost of $4.34 \mathrm{M}$ Euro for the first section and 8.61 M Euro for the second one. The information about the construction costs has been collected from the informative studies of the corresponding projects.

\section{Infrastructure Maintenance Costs}

The annual maintenance cost for the infrastructure has been estimated at 11.750 Euro per km, taking as reference the average value of the costs of the Madrid-Seville AVE and the Madrid-Barcelona AVE, which are already operative.

It is important to point out that in the long term aspect, this cost category is probably slightly sensitive to the levels of demand. This effect has not been considered, as it has been assumed that it would be offset by a probable downward trend of the maintenance unit costs.

By admitting the possibility of transporting cargo, this cost has been increased by $50 \%$. This increase is justified by the data collected from the economic data from the economic - financial annual report of the rail company RENFE, referred to the maintenance costs of the infrastructure both for the AVE used only for passenger transport (as in the case of Madrid-Sevilla) and for the maintenance of the conventional infrastructure used both for passengers and freight. Is has been assumed that maintenance costs of the infrastructure are the same for the section Madrid-Sevilla as for the section Palencia-Santander. More information on this topic is available in [7-10].

\section{Rolling Stock Costs}

The costs considered for the different types of rolling stock (locomotive and wagons) are as follows: 13.11 million Euros for long-distance trains; 11.04 for regional shuttle trains; and 9.43 for cargo trains. These costs have been calculated taking into account that the route does not necessarily require it to be high technology, given that the speed being aimed for is $250 \mathrm{~km} / \mathrm{h}$ instead of $350 \mathrm{~km} / \mathrm{h}$, according to data provided by the Spanish Ministry of Public Works.

\section{Costs for Obtaining the Necessary Rolling Stock Units}

Following [2], the methodology used to determine the necessary units of rolling stock is as follows. The average capacity of trains is 228 passengers. Besides, it has been assumed that the occupancy rate is $60 \%$ and the average mileage covered by each unit is 400,000 kilometres per year. Therefore, a new train would be needed every 54.72 million passenger-km.
For shuttle rail vehicles, a $60 \%$ occupancy rate has been considered. Given that their capacity is 238 travellers and also taking into account that a train covers 400,000 kilometres per year, the result obtained is that it would be necessary to incorporate a new train every 57.12 million passenger-km.

Lastly, applying the same methodology, it has been established that, for the transport of cargo, a new train would be needed every 24.8 and 49.6 million tonnes / kilometre, depending on whether it is full cargo or combined transport.

It is necessary to highlight that the calculations are based on ideal operating conditions or maximum efficiency conditions in the incorporation of the new rolling stock.

\section{Operating Costs}

This category includes all costs derived from operating the AVE (power, staff, maintenance of rolling stock and services, such as catering, video, etc.), taking as reference the operating costs of the Madrid-Seville line. The cost for the transport of passengers is 8.21 Euro cents per passenger $/ \mathrm{km}$. For the transport of freight, the cost of operation is 4 Euro cents per tonne $/ \mathrm{km}$. The source used to obtain this information is the Economic - Financial Annual Report of RENFE and its economic data.

\section{Residual Value}

For the rolling stock, the useful life considered is 20 years, assuming as well a linear depreciation during this period.

For the infrastructure category, in [11] the useful life values are calculated separately, referring to the different categories which constitute the infrastructure, such as electricity and safety installations. As an average of the different categories and land considered, it has been estimated a value of 45 years for the entire infrastructure. Therefore, after 40 years of operation, and assuming a linear depreciation, the residual value will be minimal, approximately $10 \%$ of the value of the investment made.

\subsection{Monetary Income from Generated Trips}

The initial demand in the corridor before the introduction of the AVE for each mode of transport has been determined using data of the operating transport companies and the mobility surveys made, see $[12,13]$.

On the basis of the results for the Madrid-Sevilla AVE $[14,15]$, the factors for substitution and generation of demand for new trips have been defined.

Likewise, the same time elasticity value as that obtained for the Madrid-Seville AVE has been used to estimate the size of the demand of AVE passengers for this SantanderMadrid corridor.

In the case of cargo transport on the AVE, the magnitude considered for the time elasticity necessary for determining the initial AVE cargo traffic is 0.8 according to [16].

For the application of this methodology, it is not only necessary to know the initial demand of the AVE, but also its evolution during the operation period considered, divided into its two components: generated traffic and diverted 
traffic, as well as the income needed for the assessment of the benefits produced by the generated trips.

In order to address this question, it has been assumed that during the first year of operation only $80 \%$ of the expected demand for 2016 will be met. In other words, it is assumed that as from 2016 the AVE demand will evolve in parallel to the growth of the Spanish GDP, with an elasticity of 1.4. This value is similar to the one obtained in Spain's air transport sector [17] and is also in line with those obtained in other countries [18]. Along these same lines [19], holds that the French $\mathrm{TGV}$ is more similar to an airplane than to a conventional train.

This same value has been considered for the case of cargo transport. This way, the cargo railway can slowly recover modal share with regard to road transport, which elasticity with regard to the GDP is 1.2 .

\section{Induction}

The component of the AVE demand, usually termed induced, is comprised by all the new trips. This "generation effect" must not only include passengers who have never made such a trip, but also another component formed by the increased frequency of trips by those who were already travelling on that route before the existence of the AVE. The average of annual trips made by users in the Madrid-Seville route increases very significantly, from 11.1 to 15.2 . This induction phenomenon has been occurring for a period of 4 years after the AVE line Madrid-Sevilla began operating.

Based on the results of the Madrid-Seville AVE, the substitution and generation factors for the new demand for trips have been established. Thus it has been estimated that, in the case of the Santander-Madrid AVE, generated or new trips would represent $13 \%$ for the Santander-Madrid route, and $7.5 \%$ for the rest of the routes.

\section{Substitution}

Likewise, the introduction of the high speed train produces significant effects on the demand of the rest of the means of transport, given its competitive advantages in the different components of the generalised cost (travel time, punctuality, comfort, etc.) with regard to other means of transport.

Table 2 shows the changes estimated to take place in the modal distribution of the demand in the Santander-Madrid route as a result of the introduction of the AVE.

Table 2. Change in the Modal Distribution in the SantanderMadrid Route. (Thousands of Passengers in Both Directions)

\begin{tabular}{|l|c|c|c|c|}
\hline $\begin{array}{c}\text { Means of } \\
\text { Transport }\end{array}$ & $\begin{array}{c}\text { Before the } \\
\text { AVE }\end{array}$ & $\mathbf{( \% )}$ & $\begin{array}{c}\text { After the } \\
\text { AVE }\end{array}$ & (\%) \\
\hline \hline Private vehicle & $1,588.1$ & 64.2 & $1,318.1$ & 47.1 \\
\hline Airplane & 274.3 & 11.1 & 164.8 & 5.9 \\
\hline Bus & 465.8 & 18.8 & 419.2 & 15.0 \\
\hline Conventional Train & 147.2 & 5.9 & 22.1 & 0.8 \\
\hline AVE & ------ & ------ & 874.5 & 31.2 \\
\hline
\end{tabular}

Source: Authors' compilation based on the Madrid-Seville AVE results.
Table 3. Traffic of Passengers and Cargo on the SantanderMadrid Route High Speed Train (Both Directions in Year 2016)

\begin{tabular}{|c|c|c|}
\hline & $\begin{array}{c}\text { Passengers } \\
\text { (Thousands) }\end{array}$ & $\begin{array}{c}\text { Cargo } \\
\text { (Thousands of Tonnes) }\end{array}$ \\
\hline Santander- Madrid & 874.5 & 736.5 \\
\hline Santander-Valladolid & 361.9 & 172.8 \\
\hline Santander-Palencia & 271.6 & 764.1 \\
\hline Santander-Torrelavega & 141.1 & 465.4 \\
\hline \multirow[t]{2}{*}{ TOTAL } & $1,649.1$ & $2,138.8$ \\
\hline & $\begin{array}{c}\text { Passengers- } \\
\text { Kilometres } \\
\text { (Million) }\end{array}$ & $\begin{array}{c}\text { Cargo } \\
\text { (Millions of Tonnes -Kilometres) }\end{array}$ \\
\hline Santander- Madrid & 446.0 & 375.6 \\
\hline Santander-Valladolid & 105.0 & 50.1 \\
\hline Santander-Palencia & 55.7 & 156.7 \\
\hline Santander-Torrelavega & 4.9 & 16.3 \\
\hline TOTAL & 611.6 & 598.7 \\
\hline
\end{tabular}

The magnitude reached by this substitution effect in the Santander-Madrid route for each mode of transport, expressed as a percentage of reduction of its demand, is as follows: conventional railway $-85 \%$, airplane $-40 \%$, private vehicle $-17 \%$ and coach $-10 \%$. For the latter mode of transport the impact is not significant, given that neither private vehicle nor coach are really substitutes.

Based on the results shown, it could be concluded that the introduction of the high speed train produces a drastic change in the modal distribution of demand, it being possible to divide the transport market before and after the AVE introduction. Thus, the entry into operation of the high speed line will make it possible to invert the current participation trend of the railway, both in the transport of passengers and in the transport of cargo.

Table 3 shows the traffic of passengers and cargo to be absorbed by the high speed train in 2016. It also shows an interesting piece of information for carrying out this project's cost-benefit analysis: the traffic of passengers and cargo expressed as passenger-kilometres and tonnes-kilometres, obtained from multiplying the number of passengers and tonnes by the respective distances.

\subsection{Benefits}

Below the categories of benefits considered in the project and the methodology used for their assessment are detailed.

However, the macroeconomic, sectorial and regional effects analysed in depth by [20-22] have not been taken into account.

A first category of the benefits, inherent to the operation of the new product, consists of the reduction of costs in the alternative means of transport: conventional railway, airplane, coach and private vehicle.

\section{Reduction of Costs in Conventional Railway}

The intermodal substitution produced by the AVE is especially pronounced for the conventional railway, which 
practically becomes a marginal mode of transport on this route in terms of its passenger transport function.

In order to determine the corresponding cost reduction, the structure of the production cost of the average daytime train has been used, it being the most affected by the reduction of the service supply. Of all its components, only half of the cost associated to the category of stations has not been included. However, the entire amortisation category has been included, based on the fact that the train could be used alternatively in another route.

As the offer along this route has practically disappeared, in order to determine the total cost it is valid to use a unit cost ratio per passenger-km, which has been obtained by applying to the national average value a coefficient representing the occupancy differential existing in this route with regard to the national average.

This has been estimated at 4.63 euro cents for the year 2008 per traveller-kilometre originating from conventional train travel.

Calculations have also been made for the case of railway transport of cargo.

\section{Reduction of Costs in Air Transport}

The transfer of travellers from air transport to the AVE brings about a reduction in costs for air transport operators in the Santander-Madrid route. In this mode of transport, unlike the case of the conventional train, aside from the cut in the number of flights the reduction of the offer takes place through a reduction of the average occupancy.

For this reason, instead of being used on a unit cost per traveller-km, the method used is based on establishing the reduction of the number of flights in order to obtain the cost savings for the trip by applying the average cost of a flight.

The cost savings per unit per trip have been obtained by subtracting from the total cost the fixed items such as structural costs and part of the commercialisation costs, as well as all taxes. The amortisation category has been kept, given that an aircraft can be used on another line, as clearly understood when the operator is renting the aircraft.

The final result is 15.23 Euro cents for the year 2008 per passenger-km originating from air travel.

\section{Reduction of Costs in Coaches}

In coaches, the effect of the intermodal substitution brought about by the introduction of the AVE generates cost savings for the operating companies, essentially as a result of the reduced number of trips. In order to calculate these savings, the costs structure of a representative coach has been used; according to [23], the average total costs for coaches amount to $1.51 € / \mathrm{km}$.

By applying an average occupancy factor of $70 \%$ on this mode of transport, the result is savings of 3.92 Euro cents per passenger-km originating from coach travel.

\section{$\underline{\text { Reduction in Lorry Costs }}$}

The method used has been the same as for the above sections. In order to calculate the savings, the costs structure of a representative lorry has been used; according to [23], the costs of a lorry amount to $1.09 € / \mathrm{km}$.
Taking into account that the useful load of a representative lorry is $25,000 \mathrm{~kg}$, i.e. 25 tonnes, savings of 4.36 euro cents per tonne-km originating from lorry travel have been calculated.

\section{Reduction of Car Costs}

In the case of private vehicles, it is not possible (except if the vehicle is rented) to substitute the trip planned initially by another one in a different place during the same period of time. Therefore cost categories considered as "fixed", such as part of the amortisation and insurance, should not be included in determining cost savings. As to the part of the amortisation category included, [5] has been used as reference, where it is estimated that half of the mentioned category corresponds to the passing of time, whereas the other half is related to the use of the vehicle.

Continuing with this assumption, the structure of the cost savings has been obtained, eliminating the fixed categories as well as the taxes, for each of the routes that make up the corridor. With the aim of obtaining greater precision in the results, these routes have been broken down into several sections which are similar with regard to traffic. The costs considered in each section and for which specific methods have been used are: vehicle amortisation, maintenance, fuel consumption, lubricant consumption and tyre wear.

The calculated savings per unit amount to 52.87 euro cents per passenger-km.

\section{Time Savings for Travellers on the High Speed Train}

A category of the benefits related to the introduction of the AVE consists of the time savings for passengers originating from other means of transport and also for new passengers.

For its assessment, it is necessary to know the modal travel times from the origin to the destination for each means of transport (including the times to and from the station or airport) and the monetary values assigned to the total travel time.

Likewise, in order to calculate the savings corresponding to the generated trips it is necessary to have access to the monetary costs of each means of transport, which makes it possible to obtain the income.

The product of the time savings (expressed in hours) by the value of the time hour defines this benefit category. Thus, the values of times considered in Euros per hour per passenger per tonne are the following: 7.36 (car); 31.15 (airplane); 3.97 (coach); 15.86 (train, passengers); 3.40 (lorry); and 3.40 (train, cargo).

\section{Reduction of External Costs}

For the assessment of external costs, the methodology and the results of [6] have been considered. The end values for the modal social costs per unit are shown in Table 4.

A brief summary of the methodology used for calculating the mentioned costs is the following:

\section{Cost Savings Due to Congestion Reduction}

The introduction of the AVE implies a reduction in the volume of the traffic on the affected roads in the SantanderMadrid route. This reduction brings with it an increase in speed, and therefore a decrease in the journey time for vehicles (cars, coaches and lorries) which remain on the road. 
Table 4. External Marginal Social Costs Per Means of Transport. (Euro Cents Per Passenger or Tonne-Km)

\begin{tabular}{|c|c|c|c|c|}
\hline & Environmental & $\begin{array}{c}\text { Infrastructure } \\
\text { Conservation }\end{array}$ & Accidents & Congestion \\
\hline \hline Car & 1.89 & 0.84 & 3.05 & 2.14 \\
\hline $\begin{array}{c}\text { Train } \\
\text { (passenger) }\end{array}$ & 0.60 & 2.62 & 0.17 & - \\
\hline Coach & 0.67 & 0.16 & 0.78 & 0.37 \\
\hline Airplane & 2.46 & - & - & - \\
\hline AVE & 0.49 & - & - & - \\
\hline Lorry & 3.57 & 1.58 & 3.53 & 2.14 \\
\hline $\begin{array}{c}\text { Train } \\
\text { (cargo) }\end{array}$ & 1.61 & 3.50 & 0.15 & - \\
\hline
\end{tabular}

The significance of this benefit can be assessed by multiplying the average savings in time of road users by the value of time.

To quantify this externality it is necessary to determine the existing relationship between the volume of traffic and speed, for the cases of motorway and conventional road. In order to attain greater effectiveness, two curves in the shape of a parabola and a straight line respectively have been adjusted to the graphs, obtaining the following algebraic expressions:

$\mathrm{V}=48+72(1-\mathrm{i} / \mathrm{c})^{1 / 2}$ For Motorways

$\mathrm{V}=100-22(\mathrm{i} / \mathrm{c})$ For conventional roads

where $V$ is the speed of light vehicle, $i$ is the Intensity of traffic per hour and $c$ is the Road capacity.

The speed of heavy vehicles is determined by the following expression:

$\mathrm{V}_{\mathrm{p}}=0.52 \mathrm{~V}+28.85$

Strictly speaking, the speed for each hour of the year should be calculated using these formulae in order to determine the average speed. However, results show that the margin of error is very slim. Taking this into account, it was considered that other methodology would be more effective, having been for this reason, the hours of the year grouped in intervals of frequency, in accordance with the traffic intensity values per hour.

On the basis of the speed values obtained for each of the intervals and by means of the application of the corresponding weighted mean, the annual average speed for each selected section of the route has been obtained, using the volume of traffic given by its corresponding traffic flow meter.

With this methodology, it is possible to determine the speed and therefore the journey time for each selected section for both options, with and without the AVE. By aggregating the sections, the reduction in times is obtained, in the sections that make up the analysed corridor both for light and heavy vehicle.

Lastly, by means of the monetary values of time mentioned in the corresponding section, the cost savings brought about by reduced congestion on the roads are obtained. This benefit is only considered for road transport.
Savings Brought About by a Reduction in the Number of Accidents

The introduction of the high speed train in the route Santander-Madrid brings about a drop in the number of passengers (car and coach) on the roads of the mentioned route, and therefore a reduction in the number of accidents on the route. Following [4] a unit value for the elasticity of the number of accidents with regard to the traffic is assumed; therefore, in order to calculate the external social cost of accidents, it is only necessary to take into account the non-internalised costs by means of the corresponding policies.

Following the recommendations of the European Commission a base human life value of 0.93 million Euros has been used.

Likewise, the external cost of accidents in the conventional railway has been determined. The addition of both costs is the benefit associated to the reduction in the number of accidents due to the lower number of passengers on the road and on conventional trains.

\section{Maintenance Costs Savings}

Due to the substitution effect, the introduction of the AVE in this route causes a reduction in the number of vehicles (cars, coaches and lorries) on the affected road network, which in turn translates into a reduction of maintenance costs supported by the corresponding public administrations and not by the user. The same occurs with the conventional railway, where there is a reduction of the maintenance costs of the railway infrastructure of this route (not supported by users with their tickets), due to the reduction in the number of passengers caused by the introduction of the AVE.

In order to calculate these cost savings, the maintenance unit costs per vehicle-km for cars, coaches and lorries mentioned in the table above have been used. In essence, the methodology employed consists in distributing the different categories that make up the maintenance costs of the road network and which are supported by the respective public administrations, among the different types of vehicle (cars, buses and coaches) in accordance with the criteria chosen (axle weight, equivalent vehicles, etc.). The sum of these components for each type of vehicle determines its unit cost for infrastructure conservation. Likewise, for the railway, costs of preserving the railway infrastructure among passengers and cargo are distributed, using a similar method.

\subsection{Sensitivity Parameters}

\section{The Discount Rate Parameter}

In order to determine the final net benefit of the project, it is necessary to update the annual benefits and costs with regard to the year considered as base, by means of a real social discount rate $r$, in such a way that the present value of the investment is:

$$
V A N=\sum_{t=0}^{n} \frac{B_{t}}{(1+r)^{t}}-\sum_{t=0}^{n} \frac{C_{t}}{(1+r)^{t}}
$$

where $B_{t}$ and $C_{t}$ represent a project's benefits and costs in time, respectively.

The Manuals for the assessment of projects of the Spanish Ministry of Public Works, responsible for transport infrastructure, recommend the use of a social discount rate of 
$6 \%$ in real terms. This value has also been used in other infrastructure projects (especially roads) developed in Spain during the nineties.

However, since the incorporation of the Spanish Economy to the European Economic and Monetary Union, the consolidation of favourable economic expectations has translated into a consolidation of low values of real interest rates below 3\%. Therefore, it seems logical to use a magnitude of $4 \%$ for the real discount rate in the medium term as a basic alternative in the assessment of the model project.

\section{Project Duration Parameter}

It has been considered that the project's life period is 40 years and, alternatively, with a sensitivity analysis of 60 years.

\section{Economic Growth Rate Parameter}

It has been assumed that the annual GDP growth rate is 3\% during the entire project. This value would correspond to the growth rate of the potential Spanish GDP according to many studies carried out on the Spanish economy.

For the sensitivity analysis, annual economic growth rates of $2.5 \%$ and $3.5 \%$ are considered.

\section{Human Life Value Parameter}

The recommendations of the European Commission place the value of human life around 0.93 million Euros.

In the sensitivity analysis a value of 1.39 million Euros is considered, $50 \%$ higher that recommendations of the European Commission.

\section{RESULTS: VALUATION OF THE PROJECT IN BOTH ITS ALTERNATIVES}

In the base case scenario $n$, a basic value of the different parameters is considered; 3\% GDP growth, 40 years' duration of the project, a social discount rate of $4 \%$, a period for the execution of the investment of 6 years and 0.93 million Euros as the human life value.

Also, it is assumed that the prices of the goods and services used vary during the life of the project, in line with the general inflation rate. This way the real prices are constant during the life of the project.

The indicators used to quantify the assessment criteria are always calculated by means of the variation between the situation of reference or without project (object under assessment, which will be called base case scenario), and the scenario that incorporates the project under study (situation with project). Thus, for instance, time saving is calculated through the difference between the time needed by every user of the transport system in the situation with or without the project.

Using the methodology mentioned above and the parameter and demand values obtained, a cost-benefit analysis of the high speed railway between Santander and Madrid has been carried out.

This assessment has been developed in two stages. In a first stage, the project's net social benefit has been obtained, on the basis of only passengers being transported. In the second phase, the additional net social benefit brought by cargo transport via the high speed train line has also been considered, in line with the content of the Spanish Infrastructure and Transport Strategic
Plan (Plan Estratégico de Infraestructuras y Transportes or PEIT).

\subsection{Passengers Alternative}

The information displayed on the second column 2 of Table 5 (AVE Benefits, Passengers) shows the results of the social assessment of the high speed Santander-Madrid train if only passenger traffic is to be considered. It shows that the present discounted value of the net social benefits is 67.41 million Euros in 2008. That is, the social benefits exceed the social costs on 67.41 million Euros.

\subsection{Combined Passenger and Cargo Option}

On Table 5 none of the added costs of the infrastructure have been included, when it is also used for cargo transport, as it is assumed that construction costs already include the possibility of transporting freight. Lastly, the third column of Table 5 shows the results of the project's cost-benefit analysis, simultaneously considering the transport of passengers and cargo. In this case the project is socially profitable given that the present discounted value of its benefits is 366.59 million Euros.

Likewise, the internal rate of return (IRR) obtained in the assessment of this project is $5.10 \%$.

In other words, the consideration of the traffic of cargo drastically improves the results of the project's profitability, as the increase of the benefits is significantly higher than the additional costs.

Also, a sensitivity analysis has been carried out with regard to the most important variables for the profitability of the project, and the IRRs obtained are as follows: Duration of the project (60 years), IRR 6.24\%; human life value (1.39 million Euros), IRR 5.58\%; and financial growth rate (2.5\% and 3.5\%), IRR $4.39 \%$ and $5.80 \%$, respectively.

\section{CONCLUSIONS}

The results of the cost-benefit analysis carried out clearly show that the high performance railway project in its combined passenger and cargo option is the most economically profitable option.

In the project's base case scenario, simultaneously considering the transport of passengers and cargo, the updated value of its net social benefits is 366.59 million Euros. This corresponds to an IRR value of $5.10 \%$.

The final balance of the project is therefore positive and makes evident the economic performance that will be brought about by its implementation.

Besides, it is also important to highlight that the analysis has not considered other positive effects of a transitory nature which take place during the implementation of the project and which will especially affect production and employment, nor has it considered the effect of an infrastructure of this kind in attracting logistics operators and industrial and service companies. In addition, the importance of the infrastructure for the region's economic development is also not taken into account. Implementing the project will undoubtedly provide Cantabria with a significant growth boost.

It is important to point out that the sensitivity analysis carried out confirms the results obtained for the base case scenario. The net social benefit is positive for the different 
hypotheses regarding the parameters modulating the profitability of the project. The high economic profitability of the project is maintained given that all the IRR values easily exceed $4 \%$, with an approximate rate of return of $5.5 \%$ in real terms. In nominal terms, the size of the rate of return would be substantially higher given that it would have to be increased with the corresponding price growth rates (around 3\% as a trend value).

Table 5. Social Benefit of the High Speed Train in the Santander-Madrid Route. (Case of Passenger Transport and Case of Passenger and Cargo Transport). Millions of Euros in 2008

\begin{tabular}{|l|c|c|}
\hline & $\begin{array}{c}\text { AVE Benefits } \\
\text { (Passengers) }\end{array}$ & $\begin{array}{c}\text { AVE Benefits } \\
\text { (Passengers } \\
\text { and Cargo) }\end{array}$ \\
\hline \hline Total cost of infrastructure, maintenance and operation \\
\hline Infrastructure & 1230.07 & 1230.07 \\
\hline Residual value & 70.04 & 110.17 \\
\hline Rolling stock & 395.49 & 703.23 \\
\hline Infrastructure Maintenance & 144.30 & 216.45 \\
\hline Operation & 1383.22 & 2012.96 \\
\hline Time savings of users from: & \multicolumn{2}{|l|}{} \\
\hline Other means of transport & 651.25 & 1070.88 \\
\hline Income for Generated Trips: & 735.54 & 940.01 \\
\hline Reduced costs in: & \multicolumn{3}{|l}{} \\
\hline Conventional railway & 146.86 & 434.24 \\
\hline Airplane & 304.64 & 304.64 \\
\hline Coaches & 44.97 & 44.97 \\
\hline Car operation costs & 735.89 & 735.89 \\
\hline Lorry operation costs & - & 255.76 \\
\hline Congestion & 57.96 & 93.73 \\
\hline Accidents & 224.25 & 350.41 \\
\hline Environment & 102.35 & 125.93 \\
\hline Infrastructure Maintenance & 146.74 & 412.28 \\
\hline Present discounted net \\
value of the AVE
\end{tabular}

Source: Authors' compilation based on methodology described in the text.

All of it provides useful information and may help government decision making in terms of economic and social feasibility enabling improvements in public and/or private expenditure.

\section{ACKNOWLEDGEMENTS}

The authors gratefully acknowledge the suggestions and criticisms from two anonymous reviewers and the editor.
However, errors and omissions that may exist are the sole responsibility of the authors.

\section{REFERENCES}

[1] J. Dodgson, "Railways costs and closures", J. Transp. Econ. Policy, vol. 18, pp. 219-235, 1984.

[2] G. De Rus and V. Inglada, "Análisis coste-beneficio del tren de alta velocidad en españa", Rev. Eco. Apl., vol. 3, pp. 27-48, 1994.

[3] G. De Rus and V. Inglada, "Cost-benefit analysis of the high-speed train in spain", Ann. Reg. Sci.., vol. 31, no. 2, pp. 175-188, 1997.

[4] P. Coto-Millán and V. Inglada "Innovación en el transporte: el tren de alta velocidad", Eco. Industrial, no. 353, pp. 83-88, 2003.

[5] P. Coto-Millán and V. Inglada, "Social benefits of investment projects: the case for high-speed rail", In Essays on Microeconomics and Industrial Organization, P. Coto-Millán, Ed., 2nd ed., Heidelberg: Springer- Physica Verlag, 2003, pp. 361-385.

[6] P. Coto-Millán and V. Inglada, "Market failures: the case for road congestion externalities", In Essays on Microeconomics and Industrial Organization, P. Coto-Millán, Ed., 2nd ed., Heidelberg: Springer-Physica Verlag, 2003, pp. 343-360.

[7] A. López-Pita and F. Robusté "Compatibility and constraints between high-speed passenger trains and traditional freight trains", Transport. Res. Rec., vol. 1472, pp. 17-24, 2001.

[8] F. Robusté and A. López "Effect of very high-speed traffic on the deterioration of track geometry", Transport. Res. Rec., vol. 1825, pp. 22-27, 2003.

[9] P. López-Pita, C. Teixeira, A. Casas, Baciller and PA. Ferreira, "Maintenance costs of high-speed lines in europe state of the art", Transport. Res. Rec. (J. Transp. Res. Board), vol. 2043, pp. 13-19, 2008.

[10] K. Ebeling, "High-speed railways in germany", Jpn. Railw. Transport. Rev., vol. 40, pp. 36-46, 2005.

[11] Department of Transportation, Investment Evaluation Handbook on Broad Way Railroad, MOPT, Department of Transportation, Madrid, 1991.

[12] Department of Transportation, MOVILIA, Department of Transportation, Madrid, 2000.

[13] Department of Transportation, Permanent Survey of Road Goods Transport, MF, Department of Transportation, Madrid, 2008.

[14] V. Inglada, "Análisis empírico del impacto del AVE sobre la demanda de transporte en el corredor Madrid-Sevilla", Rev. Estu. Transport. Commun., vol. 62, pp. 35-51, 1994.

[15] P. Coto-Millán, V. Inglada and B. Rey, "Effects of network economics in high speed rail: the spanish case", Ann. Reg. Sci., vol. 41, pp. 911-925, 2007.

[16] C. Winston, "Conceptual development in the economics of transportation: an interprettive survey", J. Econ. Lit., vol. 23, pp. 57-94, 1985.

[17] P. Coto-Millán, J. Baños-Pino and V. Inglada, "Marshallian demands of intercity passenger transport in Spain. An economic analysis 1980-1992", Transport. Res. E. (Logist. Transp. Rev.), vol. 33, pp. 79-96, 1997.

[18] AD. Owen and GDA. Phillips, "The characteristics of railways passenger demand", Transport. Econ. Pol. J., vol. 21, pp. 231-253, 1987.

[19] A. Bonnafous, "The regional impact of the TGV", Transportation, vol. 14, pp. 127-137, 1987.

[20] O. Álvarez and JA. Herce, "Líneas ferroviarias de alta velocidad en españa”, Eco. Apl., vol. 1, pp. 5-32, 1993.

[21] V. Inglada, "El papel de las infraestructuras en la competitividad y el desarrollo económico", Estu. Territ., no. 97, pp. 397-409, 1993.

[22] Department of Transportation, Monitoring Costs of Passenger Transport by Coach, MF, Department of Transportation, Madrid, 2008.

[23] Department of Transportation, Monitoring Cost of Transporting Goods by Road, MF, Department of Transportation, Madrid, 2008. 